\title{
Autoantigen, innate immunity, and T cells cooperate to break B cell tolerance during bacterial infection
}

\author{
Pauline Soulas, ${ }^{1}$ Anne Woods, ${ }^{1}$ Benoit Jaulhac, ${ }^{2}$ Anne-Marie Knapp, ${ }^{1}$ \\ Jean-Louis Pasquali, ${ }^{1}$ Thierry Martin, ${ }^{1}$ and Anne-Sophie Korganow ${ }^{1}$ \\ 1Laboratoire d'Immunopathologie, INSERM U737, Centre de recherche d'immunologie et d'hématologie, Hôpital Civil, Strasbourg, France. \\ 2Laboratoire de bactériologie, Hôpitaux Universitaires de Strasbourg, Strasbourg, France.
}

\begin{abstract}
Autoantibody production during infections is considered to result from nonspecific activation of low-affinity autoreactive $B$ cells. Whether this can lead to autoimmune disease remains uncertain. We show that chronic infection by Borrelia burgdorferi of Tg animals expressing human rheumatoid factor (RF) B cells (of low or intermediate affinities) in the absence or in the constitutive presence of the autoantigen (represented here by chimeric IgG with human constant region) breaks their state of immunological ignorance, leading to the production of RFs. Surprisingly, this production was more pronounced in intermediate-affinity RF Tg mice coexpressing the autoantigen. This overproduction was mediated by immune complexes and involved synergistic signaling between the $B$ cell receptor and Toll-like receptors and $T$ cell help. These findings indicate that chronic infection can activate autoreactive $B$ cells with significant affinity and creates conditions that can drive them to differentiate into memory cells. Such cells may have some physiological yet undetermined role, but in autoimmune-prone individuals, this scenario may initiate autoimmunity.
\end{abstract}

\section{Introduction}

Susceptibility to autoimmune diseases is determined by a combination of genetic and environmental factors, the latter being mostly unknown. Among them, the role of infectious agents in the setting off or exacerbation of autoimmune diseases is still a matter of debate. Although there is substantial evidence that, in some circumstances, infections may have a protective effect against autoimmune-mediated diseases, clinical observations and several experimental models have suggested for decades that autoimmune diseases may be initiated or worsened by microbial infections (1). However, there is no real understanding of the underlying mechanisms (2). These questions have clear clinical implications.

In theory, the mechanisms by which a microbe may activate autoreactive cells could fall into 2 categories: antigen-specific and antigen-nonspecific. On one hand, the antigen-specific theory relies mainly on epitope mimicry. Indeed, cross-reactivity is frequent at the $\mathrm{B}$ cell level and even more at the $\mathrm{T}$ cell level because of the degeneracy of the $T$ cell repertoire, making this model tantalizing for immunologists. However, it has not yet been convincingly demonstrated that epitope mimicry can set off an autoimmune disease (3). On the other hand, the antigen-nonspecific mechanisms are numerous and loosely grouped under the term "bystander activation." For B cells, it has been known for decades that bacterial or viral infection, particularly when it is persistent, leads to polyclonal $B$ cell proliferation and Ig production, and that newly synthesized specific Abs constitute generally only a small fraction in the resulting hypergammaglobulinemia (4-8). The mechanisms underlying

Nonstandard abbreviations used: anti-B. burgdorferi huIgG, huIgG from patients with high serum levels of anti-B. burgdorferi IgG; BCR, B cell receptor; BSK-H medium, Barbour-Stoenner-Kelly medium; CsA, cyclosporin A; huIgG, human IgG; PAMP, pathogen-associated molecular pattern; RF, rheumatoid factor.

Conflict of interest: The authors have declared that no conflict of interest exists.

Citation for this article: J. Clin. Invest. 115:2257-2267 (2005).

doi: $10.1172 / \mathrm{JCI} 24646$ this nonspecific B cell activation are far from obvious; in particular, they are most probably not limited to cytokines released from activated $T$ cells, since they may involve cognate interactions with specific T cells (7). As recently emphasized by Silverstein and Rose, the old question of whether this polyclonal activation includes the turning on of anti-self and therefore may lead to autoimmune disease is still open (9). With current knowledge, 2 different situations can be considered. In the first, natural autoreactive $B$ cells produce only low-affinity Abs. They escape tolerance mechanisms because they fall below the threshold for induction of anergy, deletion, or editing. Then polyclonal activation would result in the production of more of these innocuous Abs with no role for the autoantigen and with no clinical consequences. On the other hand, some antiself B cells normally present in healthy subjects may have sufficient affinity to bind autoantigens and to receive some signal through the $\mathrm{B}$ cell receptor (BCR). Indeed, anti-self memory B cells expressing somatically mutated autoantibodies can be detected in normal individuals $(10,11)$. Under normal circumstances such cells would remain quiescent because a second signal is lacking or because they are kept silent by active immunological-ignorance mechanisms. The processes that allow these cells to escape normal tolerance mechanisms and that can trigger them to secrete autoantibodies are mostly unknown. In this view, important questions are: (a) do such cells participate in the polyclonal activation induced by an infection; (b) if so, by which mechanisms; and (c) can this lead to an autoantigen-driven maturation?

In order to address these issues, and to facilitate the analysis, we designed experimental infections of self-reactive $\mathrm{B}$ cell $\mathrm{Tg}$ mice. We chose Tg animals expressing a highly relevant model of human autoantibody, the rheumatoid factor (RF) (12). Indeed, B cells expressing BCRs specific for self $\mathrm{C} \gamma(\mathrm{IgG})$, known as RF B cells, are present in large numbers in the normal human repertoire in spite of the ubiquitous presence of IgG in different biological forms (free or in immune complexes, soluble or membrane bound). 

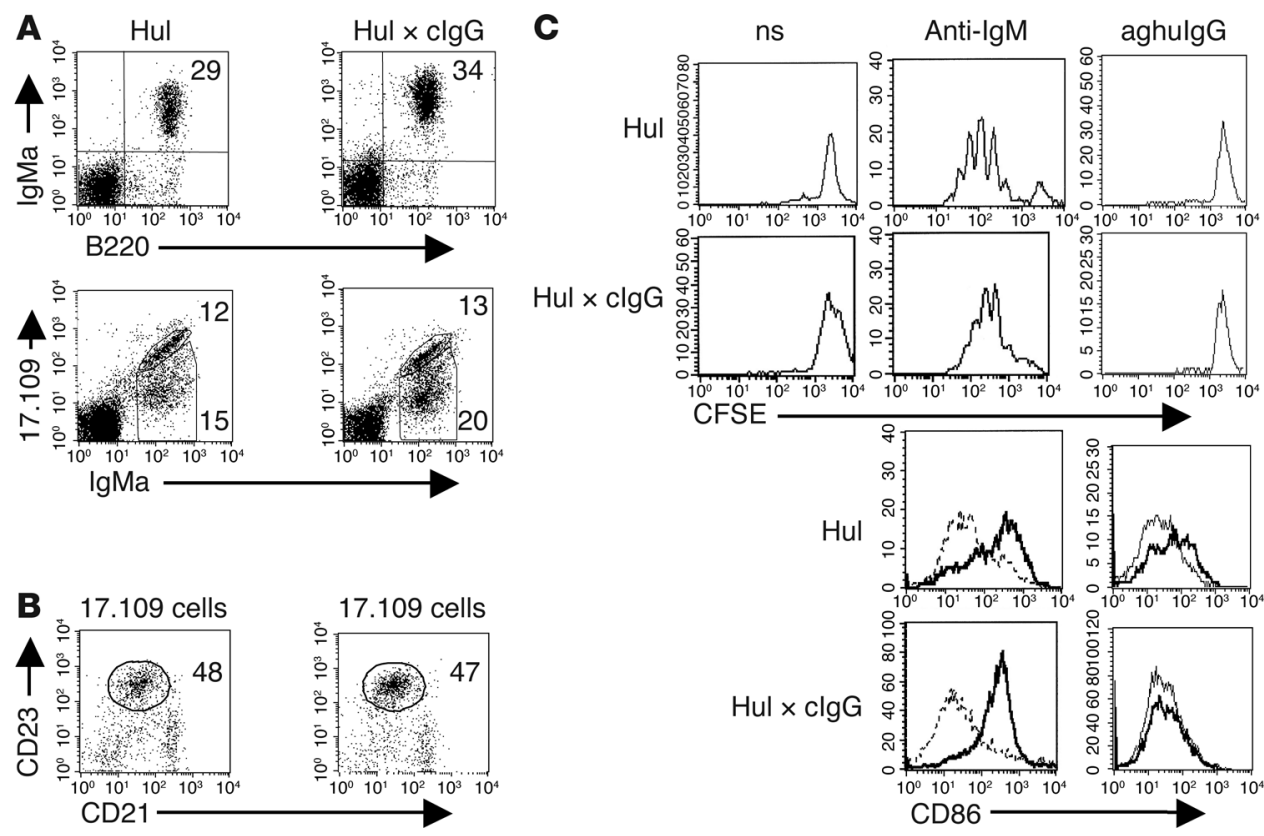

Figure 1

B cells in Hul and Hul $\times$ clgG mice. Hul $\times$ clgG RF B cells develop normally and remain functionally ignorant. (A) Flow cytometry of splenocytes from Hul and Hul $\times$ clgG mice. Viable lymphocytes are gated on forward scatter (FSC) and side scatter (SSC) parameters. B220 staining reflects total B cells; IgMa is the Tg heavy chain allotype; 17.109 is the Tg light chain idiotype. Numbers indicate the mean percentage in the quadrants or the outlined gates. (B) Percentages of follicular B cells assessed by CD21 and CD23 expression on splenic $17.109^{+}$cells. (C) Effects of in vitro stimulations on Hul and Hul $\times$clgG splenic B cells. Splenocytes were cultured for 72 hours in the presence of aggregated hulgG (aghulgG, $1 \mathrm{mg} / \mathrm{ml}$ ), anti-mouse lgM $(10 \mu \mathrm{g} / \mathrm{ml})$, or medium alone (nonstimulated [ns] or dashed line). Histograms show divisions of CFSE-labeled $17.109^{\text {high }} \mathrm{B}$ cells or surface expression of the CD86 activation marker on these cells.

Under normal conditions, RF B cells seem autoantigen ignorant and do not secrete RF. However, RF B cells can be activated in many autoimmune conditions, but also in nonautoimmune conditions and in particular during infectious diseases. Thus, we used 4 different lines of Tg mice expressing chimeric RFs (human variable regions, mouse IgM and IgD constant regions) that differed mainly by the affinity of the RFs for human IgG (huIgG), and by the absence or the constitutive presence of human $C \gamma 1$. Briefly, Smi RF Tg mice (previously designated nAAb; ref. 13) were constructed with a low-affinity $\left(K_{\mathrm{d}}=10^{-6} \mathrm{M}\right)$ polyreactive human RF. The autoreactive $B$ cells of these mice are self antigen ignorant (i.e., they are not activated after encountering huIgG), even in the presence of the constitutive expression of chimeric IgG (cIgG; mouse variable regions, human $C \gamma 1$ region) (14); this mimics the physiological situation in humans. Hul RF Tg animals express somatically mutated $\mathrm{V}$ regions of a monoreactive and higher-affinity $\left(K_{\mathrm{d}}=10^{-8} \mathrm{M}\right)$ human RF, and their surface $\operatorname{IgM}^{+} \operatorname{IgD}^{+}\left(\operatorname{sIgM}^{+} \operatorname{sIgD} \mathrm{D}^{+}\right)$autoreactive $B$ cells are also ignorant after in vivo injections of huIgG (15). The fourth line of RF Tg mice also expresses Hul RF, but in the constitutive presence of $\mathrm{CIgG}$, and is described in the first part of Results. Albeit there are some phenotypic differences among these $\mathrm{Tg}$ lines, their general features are the following: $\operatorname{sIgM}^{+} \mathrm{sIgD}^{+} \mathrm{RF}$ B cells develop normally in the bone marrow, localize in the $\mathrm{B}$ zones of the secondary lymphoid organs, are not activated in the presence of huIgG, and without features of anergy (they can be activated through BCR-dependent and -independent pathways).
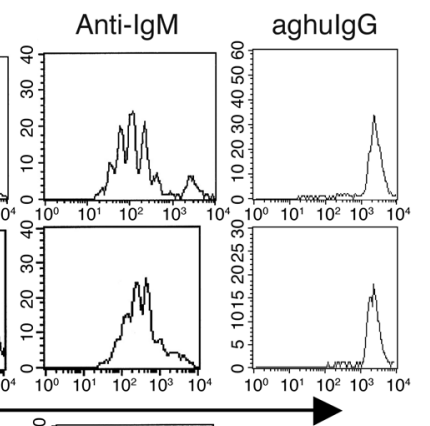

In the present study, we examine whether an experimental infection with Borrelia burgdorferi, a chronic infectious disease that is known to be associated with polyclonal hypergammaglobulinemia in both humans and mice (16), can break this state of immunological ignorance, and, if so, by which mechanisms. Our different $\mathrm{Tg}$ models allow us to study the potential roles of the autoantigen and of the affinity of the RF.

\section{Results}

Brief presentation of $\mathrm{Hul} \times \operatorname{cIgG}$ mice. Given the potential role of membrane IgD in B cell tolerance (15), all the $\mathrm{Tg}$ lines used in this study coexpress the IgM and $\operatorname{IgD}$ isotypes of the $\mathrm{Tg} \mathrm{H}$ chain. The $\operatorname{Tg} \mu$ and $\kappa$ chains are detected by an anti- $\mu$ a reagent and 17.109 anti-idiotypic mAb, respectively. By crossing Hul Tg mice with cIgG knock-in mice, we generated animals designated Hul $\times$ cIgG that express both the chimeric Hul RF and a repertoire of $\operatorname{cIgG}$ with human $\mathrm{C} \gamma 1$ region and murine variable regions $(14,17)$. In these animals, mean serum cIgG levels range between 150 and $200 \mu \mathrm{g} / \mathrm{ml}$. As judged by triple immunofluorescence analysis with anti-IgMa, 17.109, and anti-huIgG, cIgGs were produced by a small proportion of IgMa-17.109- B cells that were present in the spleens (about 2\%), excluding a cis effect (ref. 14 and data not shown). Rather unexpectedly, Hul RF B cells develop normally, populate the secondary lymphoid organs, and remain functionally naive, despite the fact that they are able to bind huIgG and cIgG at $50 \mu \mathrm{g} / \mathrm{ml}$ (ref. 15; and P. Soulas, unpublished results). Hul and Hul $\times$ cIgG mice had similar numbers of splenic B cells $\left(18 \times 10^{6} \pm 5 \times 10^{6}\right.$ and $16 \times 10^{6} \pm 6 \times 10^{6}$, respectively), and $\mathrm{IgMa}^{+} 17.109^{+} \mathrm{B}$ cells that stained diagonally with the $2 \mathrm{Abs}$ represented approximately $40 \%$ of total B cells in the spleen and LNs in both Tg mice (Figure 1A and Figure 2A, respectively). Most of the other $\mathrm{B}$ cells expressed the $\mathrm{Tg} \mathrm{H}$ chain but were $17.109^{\text {low } /-}$. We previously showed that these cells express endogenous $\mathrm{L}$ chains and do not bind huIgG and therefore can be used as an internal control (15). Three- and 4-color FACS analysis indicated that most $\mathrm{IgMa}^{+} 17.109^{+} \mathrm{B}$ cells were $\mathrm{CD} 23^{+} \mathrm{CD} 21^{+}$and expressed basal levels of CD86, CD44, and CD69, a phenotype typical of naive follicular B cells (Figure 1, $B$ and $C$, and data not shown). Although they could not be stimulated by huIgG either in monomeric form or aggregated, Hul RF B cells from $\mathrm{Hul} \times \mathrm{cIgG} \mathrm{Tg}$ animals were not anergic. Their levels of BCR and CD86 expression were similar to those of Hul RF B cells from Hul Tg mice (Figures 1A and 2A), and they could be stimulated by anti-IgM Ab (Figure 1C). In summary, mature Hul RF B cells seem to behave similarly to mature Smi RF 
A Uninfected

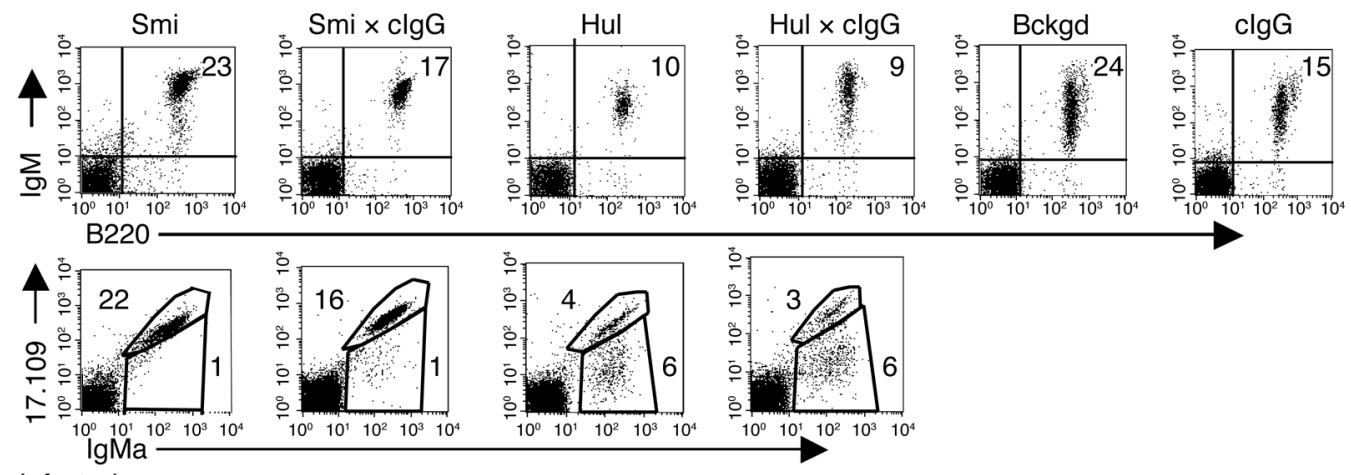

B Infected
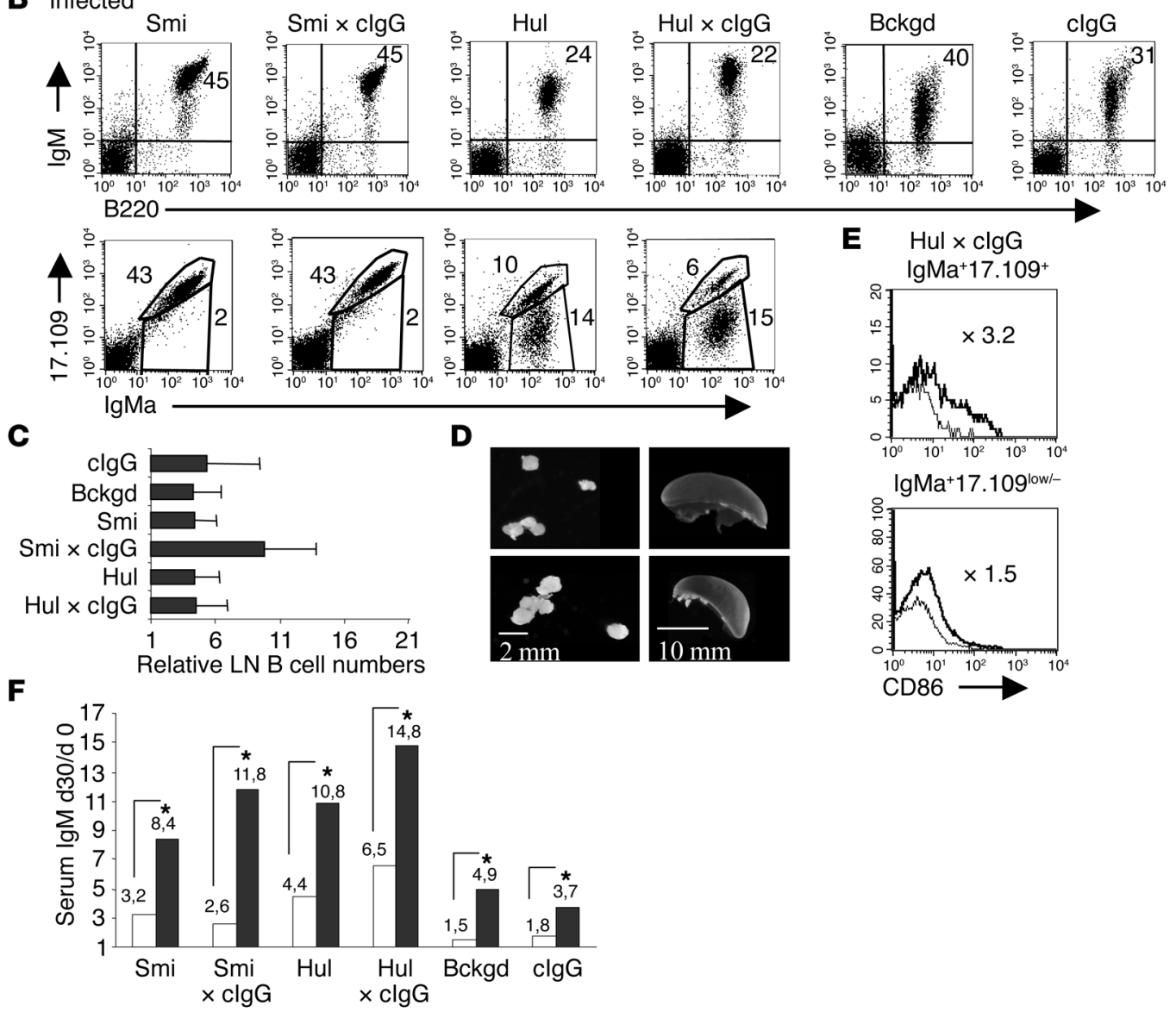

Figure 2

LN B cells in RF Tg infected mice compared with uninfected mice. B. burgdorferi infection is associated with B cell activation and IgM production. Intermediate-affinity RF B cells appear specially sensitive to activation. (A and B) Flow cytometry analysis of LN cells from infected and uninfected mice. Analysis was performed as in Figure 1A. Numbers indicate the mean percentage for $5-13$ mice. Differences between percentages of cells from infected versus uninfected mice are statistically significant for all lines $\left(P<0.05\right.$, Mann-Whitney test). (C) Numbers of lgM+B220 $0^{+}$cells in infected animals, determined by cytofluorimetry in pooled LNs, relative to uninfected controls. Each value $\pm 1 \mathrm{SD}$ represents the mean ratio from 5-13 mice. (D) Lymphadenomegaly in infected animals. Shown are spleen and inguinal LNs from an infected Hul $\times$ clgG mouse (bottom), compared with the uninfected control (top). (E) Surface expression of CD86 on gated RF B cells (IgMa+17.109+) and non-RF B cells (IgMa+17.109low/-) 30 days after $B$. burgdorferi infection (thick line) in the Hul $\times$ clgG line. (F) Levels of serum IgM in infected mice compared with controls. IgM levels were measured by ELISA. Values represent the mean relative increase of the total IgM production from day 0 to day 30 in infected mice (black bars) and uninfected mice (white bars). ${ }^{*} P<0.05$, Mann-Whitney test. Numbers of tested animals are those represented in Figure 3A. Bckgd, background.

$\mathrm{B}$ cells in Smi $\times$ cIgG mice. Table 1 summarizes the main genetic and functional differences among the several types of transgenic mice used in our study.
The B. burgdorferi infection model. B. burgdorferi is able to induce in many inbred mouse strains, including C57BL/6, a chronic systemic infection characterized by recurrent bacteremia and by the inva- 


\section{Table 1}

Characteristics of the different $\mathrm{Tg}$ animals

\begin{tabular}{|c|c|c|c|c|c|c|c|c|c|c|c|}
\hline & \multirow[b]{2}{*}{$\begin{array}{l}\text { VH } \\
\mathrm{Tg}\end{array}$} & \multirow[b]{2}{*}{$\begin{array}{l}\text { VK } \\
\mathrm{Tg}\end{array}$} & \multirow[b]{2}{*}{ Autoantigen } & \multicolumn{7}{|c|}{ RF B cells in LNs (\%) } & \multirow[b]{2}{*}{$\begin{array}{l}\text { Serum } \\
\text { hulgG } \\
(\mathrm{mg} / \mathrm{ml})\end{array}$} \\
\hline & & & & $\begin{array}{c}\text { Affinity } \\
\text { for } \\
\text { hulgG }\end{array}$ & $\begin{array}{c}\text { Genetic } \\
\text { background }\end{array}$ & $\begin{array}{c}\text { Cell } \\
\text { numbers, } \\
\text { LN }\left(\times 10^{6}\right)\end{array}$ & $\lg M a+17.10 g^{\text {high }}$ & $\lg \mathrm{Ma}+17.109$ low & $\begin{array}{l}\text { Serum } \\
\text { RF, } 8 \text { wk } \\
(\mathrm{mg} / \mathrm{ml})\end{array}$ & $\begin{array}{l}\text { Serum } \\
\operatorname{lgM}, 8 \text { wk } \\
(\mathrm{mg} / \mathrm{ml})\end{array}$ & \\
\hline $\mathrm{Hul} \times \mathrm{clg} \mathrm{G}$ & + & + & + & ++ & C57BL/6 & $5 \pm 3$ & $3 \pm 2$ & $6 \pm 2$ & $0.479 \pm 0.060$ & $1.1 \pm 0.4$ & $0.15 \pm 0.12$ \\
\hline $\mathrm{Hul}$ & + & + & & t+ & C57BL/6 & $4 \pm 2$ & $4 \pm 1$ & $6 \pm 1$ & $0.357 \pm 0.118$ & $0.5 \pm 0.1$ & - \\
\hline $\mathrm{Smi} \times \operatorname{clgG}$ & + & + & + & + & $\mathrm{C} 57 \mathrm{BL} / 6$ & $2.4 \pm 1$ & $16 \pm 6$ & - & $0.046 \pm 0.016$ & $0.3 \pm 0.2$ & $0.17 \pm 0.12$ \\
\hline Smi & + & + & & + & $\mathrm{C} 57 \mathrm{BL} / 6$ & $3.8 \pm 1$ & $22 \pm 5$ & - & $0.037 \pm 0.025$ & $0.2 \pm 0.1$ & - \\
\hline$L \times \operatorname{clg} G$ & & + & + & - & C57BL/6 & $2.2 \pm 1.6$ & - & - & - & $0.8 \pm 0.2$ & $0.18 \pm 0.06$ \\
\hline $\operatorname{clg} G$ & & & + & - & $\mathrm{C} 57 \mathrm{BL} / 6$ & $2.2 \pm 1.2$ & - & - & - & $0.8 \pm 0.3$ & $0.19 \pm 0.12$ \\
\hline Background & & & & - & $\mathrm{C} 57 \mathrm{BL} / 6$ & $4.3 \pm 2.8$ & - & - & - & $0.6 \pm 0.1$ & - \\
\hline
\end{tabular}

Data are expressed as the mean \pm SEM for groups of at least 5 mice. Cellular phenotypes were assessed as described in Figure $1 \mathrm{~A}$ and Figure 2. RF, IgM, and hulgG levels were measured by ELISA. Eight-week-old mice correspond to the age of sacrifice for infected mice and allow comparison.

sion of many tissues $(16,18)$. The highest concentrations of spirochetes are found in ankle joints, heart, and skin. Although Abs play an important role in controlling spirochetes, the host defense is unable to completely eradicate established infection (19). This failure is thought to be the consequence of the important potential for antigenic variation in this organism, which involves different mechanisms (20). A hallmark of murine B. burgdorferi infection is the development of an arthritis that peaks 2-3 weeks after intradermal injection of the pathogen.

In the subsequent experiments, Hul and Smi Tg mice can be compared with Hul $\times$ cIgG and Smi $\times$ cIgG, respectively, since they share the same genetic backgrounds (see Methods). Four-week-old Tg and littermate controls were injected with $10^{6}$ B. burgdorferi organisms and were sacrificed for analysis generally at 4 weeks after infection. The susceptibility of the $\mathrm{Tg}$ mice to experimental B. burgdorferi infection was evidenced by the following facts: (a) most RF Tg mice developed ankle joint arthritis 2 weeks after $B$. burgdorferi injection; (b) all the mice had a positive B. burgdorferi culture from at least 1 tissue sample (heart, ear skin, bladder) at 4 weeks; and (c) all the mice mounted a strong anti-B. burgdorferi IgG response, including a cIgG response in the relevant animals (Table 2). Infection resulted in at least a 3- to 4-fold increase in the total LN B cell numbers as compared with those in control mice injected with culture medium alone (Figure 2, B and C). The increase varied little among Tg, $\mathrm{Tg} \times \mathrm{cIgG}$, and non-Tg mice. In Tg animals, RF B cells $\left(\mathrm{IgMa}^{+} 17.109^{+}\right)$ and non-RF B cells (IgMa $17.109^{\text {low/-) }}$ were equally affected (Figure $2 \mathrm{~B}$ ). The increase was already detected by day 20 after infection and persisted at day 45 (not shown). By contrast, we found no significant modification in the splenic $\mathrm{B}$ cell populations, which is possibly consistent with the fact that, for unclear reasons, spleen generally harbors very low numbers of B. burgdorferi (21) (Table 3). Accordingly, LNs from infected mice were always significantly enlarged, whereas spleen sizes remained normal (Figure 2D).

Together these data are consistent with the facts that B. burgdorferi and its lipoproteins have been shown to possess in vitro mitogenic activity in both human and mouse B lymphocytes and that in vivo infection is associated with polyclonal hypergammaglobulinemia, only a minor fraction of which represents B. burgdorferi-specific Abs $(8,16,22,23)$.

$B$ cell marker analysis indicates that Hul RF B cells have distinctive behavior in the presence of their autoantigen. Spleen and LN B cells were analyzed by flow cytometry for levels of CD86 activation marker.
At day 30 after infection, membrane expression of CD86 was close to basal levels in LN and splenic B cells in all the strains of non-Tg mice as well as in cIgG animals (CD86 mean fluorescent intensity, increased from 1.1 to 1.5 compared with respective uninfected mice). This is in accord with previous work showing that $B$. burgdorferi infection indeed upregulates the surface expression of CD86 in B cells, but only transiently, during the first 2 weeks after infection (24). By contrast, during the same period of time, a significant increase in CD86 level was still detected in $\operatorname{IgMa}^{+} 17.109^{+}$ $\mathrm{LN}$ cells, compared with that in $\mathrm{IgMa}^{+} 17.109^{\text {low }}-$ cells, from Hul $\times$ cIgG mice (Figure 2E) $(P=0.0007)$. Interestingly, no such observation could be made for $\operatorname{IgMa}^{+} 17.109^{+}$cells from Hul, Smi, and Smi $\times$ cIgG mice, in which CD86 levels were close to baseline (not shown).

B. burgdorferi infection induced production of $R F$ that was in part dependent on the presence of the autoantigen. Consistent with previous work in wild-type animals (22), infection of Tg mice and of non-Tg littermates resulted in a 2- to 4-fold increase in the serum concentration of total IgM as compared with injection with culture medium (Figure 2F). To examine whether RF B cells were involved in the

Table 2

B. burgdorferi infection in RF Tg mice and controls

\begin{tabular}{lccc}
$\begin{array}{c}\text { Mouse strains } \\
\text { and } \mathrm{Tg}\end{array}$ & $\begin{array}{c}\text { Arthritis } \\
\text { prevalence }\end{array}$ & $\begin{array}{c}\text { Anti- } \\
\text { B. burgdorferi } \\
\text { mulgG }\end{array}$ & $\begin{array}{c}\text { Anti- } \\
\text { B. burgdorferi } \\
\text { hulgG }\end{array}$ \\
C3H & $6 / 6$ & $\mathrm{ND}$ & \\
C57BL/6 & $5 / 12$ & $\mathrm{ND}$ & \\
Background & $2 / 7$ & $3 / 3$ & \\
$\mathrm{~L} \times$ clgG & $6 / 10$ & $\mathrm{ND}$ & \\
clgG & $5 / 12$ & $7 / 7$ & $3 / 3$ \\
Smi $\times$ clgG & $18 / 18$ & $6 / 6$ & $3 / 3$ \\
Smi & $7 / 7$ & $10 / 10$ & \\
Hul $\times$ clgG & $21 / 23$ & $10 / 10$ & $8 / 8$ \\
Hul & $8 / 8$ & $3 / 3$ & \\
\hline
\end{tabular}

Mice were infected with $10^{6}$ B. burgdorferi and analyzed at day 20, 30, or 45. Arthritis was considered as an early marker of infection. Anti-B. burgdorferi IgG response was considered positive when OD values reached 0.2 plus background. Murine anti-B. burgdorferi IgGs (anti-B. burgdorferi mulgGs) were tested in non-Tg and RF Tg mice. Anti-B. burgdorferi hulgGs were tested in knock-in mice (clgG, RF Tg or non-Tg). Background mice were $\mathrm{Tg}^{-}$. ND, not determined. 
Table 3

Splenic B cells in RF Tg infected mice compared with uninfected mice

In contrast to the LN results, splenic B cells were respected during $B$. burgdorferi infection. Mice were infected with $10^{6}$ B. burgdorferi and analyzed at day 30. Data are expressed as the mean \pm SEM for groups of 5-13 mice. Analysis was performed as in Figure 1A. Percentages of follicular B cells and marginal zone B cells were assessed by CD21 and CD23 expression on splenic $17.109^{+}$cells (follicular B cells CD21+CD23+, marginal zone B cells CD21++CD23-; CD21++ expresses higher levels of CD21 than follicular B cells).

\begin{tabular}{|c|c|c|c|c|c|}
\hline & $\begin{array}{c}\text { Total cell } \\
\text { numbers }\left(10^{6}\right)\end{array}$ & $\begin{array}{l}\mathrm{B}^{\mathrm{B} 20}+\lg \mathrm{Ma}^{+} \\
(\%)\end{array}$ & $\begin{array}{c}\lg M a+17.109+ \\
(\%)\end{array}$ & $\begin{array}{c}17.109+C D 21-C^{-C D 23}+ \\
(\%)\end{array}$ & $\begin{array}{c}17.109+C D 21+C D 23- \\
(\%)\end{array}$ \\
\hline Hul uninfected & $60 \pm 16$ & $29 \pm 5$ & $12 \pm 7$ & $3 \pm 1$ & $2 \pm 0.5$ \\
\hline Hul infected & $45 \pm 22$ & $28 \pm 4$ & $12 \pm 4$ & $5 \pm 3$ & $2 \pm 0.4$ \\
\hline Hul $\times$ clgG uninfected & $51 \pm 21$ & $34 \pm 4$ & $13 \pm 6$ & $6 \pm 5$ & $2 \pm 0.8$ \\
\hline Hul $\times$ clgG infected & $50 \pm 24$ & $33 \pm 7$ & $10 \pm 5$ & $3 \pm 0.6$ & $1 \pm 0.4$ \\
\hline Background uninfected & $98 \pm 27$ & $50 \pm 8$ & - & - & - \\
\hline Background infected & $95 \pm 23$ & $55 \pm 7$ & - & - & - \\
\hline
\end{tabular}

Mechanisms of RF B cell activation. As mentioned above, B. burgdorferi lipoproteins have been reported to possess potent B cell mitogenic properties capable of stimulating polyclonal activation and proliferation and Ig production in vitro. These properties are dependent on the $\mathrm{Pam}_{3} \mathrm{Cys}$ modification of lipoproteins and involve TLRs, particularly TLR2 complexed to TLR1 (21, 25-27). Most known mammalian TLRs, including the TLR1/2 complex, signal through the adapter protein

hypergammaglobulinemia induced by B. burgdorferi infection, serum Tg RF concentrations were measured by ELISA at different times after infection. At day 30 after infection, RF levels were increased in all infected mice (Table 4). Since serum total IgM and RF naturally increase in animals between 4 and 8 weeks of age, we also compared the ratios of serum RF at day 30 after infection to serum RF at day 0 between infected and uninfected animals (Figure 3A). Interestingly, the increase of RF production resulting from $B$. burgdorferi infection was significantly higher in Smi x cIgG and $\mathrm{Hul} \times \mathrm{cIgG}$ mice than in Smi and Hul animals, respectively. In addition, this increase was most noticeable in infected $\mathrm{Hul} \times \mathrm{cIgG}$ animals compared with uninfected mice as well as with infected Hul Tg mice ( $P=0.0002$ and $P=0.0017$, respectively). The data presented in Table 4 allowed us to calculate the ratios of RF levels at day 30 between infected and uninfected animals and to show that the increase of RF production was more than $30 \%$ higher in $\mathrm{Hul} \times \mathrm{cIgG}$ mice than in Hul mice. In Hul $\times$ cIgG mice, RF represented $95 \%$ of the total serum IgM at day 30 after infection (mean RF level $1.46 \pm 0.16 \mathrm{mg} / \mathrm{ml}$ and mean IgM level $1.55 \pm 0.25 \mathrm{mg} / \mathrm{ml}$ ) versus $60 \%$ in uninfected $\mathrm{Hul} \times \mathrm{cIgG}$ controls. These data imply that during B. burgdorferi infection, RF B cells are activated by 2 different additive mechanisms: 1 is nonspecific, and the second depends on the presence of the autoantigen cIgG. Although Smi and Hul mice must be compared with caution since they are different $\mathrm{Tg}$ lines, a role for an RF-cIgG interaction in the second mechanism is further supported by (a) the fact that the overproduction of RF when cIgG was present was most noticeable in Hul animals (Hul RF affinity for IgG was roughly 2 log higher than that of Smi); and (b) the kinetic of RF production in $\mathrm{Tg} \times \mathrm{cIgG}$ mice: in Smi $\times$ cIgG mice the RF response was transient, peaking around day 30 after infection to return to base-line levels by day 45 . By contrast, in $\mathrm{Hul} \times \mathrm{cIgG}$ mice the response was more sustained (Figure 3B).

These data together with the CD86 expression analysis indicate that during B. burgdorferi infection RF B cells are activated to proliferate and to secrete RF by a nonspecific mechanism, i.e., irrespective of the BCR specificity. However, RF $B$ cells are further activated in the presence of cIgG, possibly reflecting BCR signaling. This is especially true for Hul mice; thus we focused our next experiments on these lines.
MyD88 (28). Purified B cells could be activated by a B. burgdorferi sonicate in vitro, but the proliferation was completely abolished for cells from MyD88-deficient mice (Figure 4A). As expected, Hul RF B cells from Hul $\times$ cIgG Tg mice proliferated in a dose-dependent manner in the presence of B. burgdorferi sonicate (Figure 4B). Since we previously determined that purified Hul IgM-RF does not bind B. burgdorferi antigens (ELISA and Western blot; not shown), these data together with previous studies indicate that during B. burgdorferi infection RF B cells can be activated mainly by a TLR pathway independent of BCR specificity.

However, nonspecific B cell activation does not explain why RF production is enhanced in $\mathrm{Hul} \times \mathrm{cIgG} \mathrm{Tg}$ mice compared with that in Hul Tg animals. We considered 2 not mutually exclusive mechanisms: (a) synergy between the BCR and a second receptor on the B cell surface, and (b) T cell help.

In view of the above data, candidate second receptors include members of the TLR family. Recently, Leadbetter et al. showed that AM14 RF B cells, which express a low-affinity murine Tg $\mathrm{RF}$, can be activated in vitro by chromatin/IgG complexes isolated from the serum of autoimmune mice but not by IgG alone (29). This effective activation required a synergistic engagement of the antigen receptor and a member of the MyD88-dependent TLR family, most probably TLR9, which binds hypomethylated CpG motifs. We hypothesized that a similar mechanism, possibly involving other TLRs including the TLR $1 / 2$ complex, could operate in Hul $\times$ cIgG infected animals. In this view it is worth noting that anti-chromatin IgGs were not detected in the serum of any infected mice by ELISA (data not shown). To examine further the mechanisms of RF B cell activation in Hul Tg mice,

\section{Table 4}

RF levels in uninfected and infected mice

\begin{tabular}{|c|c|c|c|}
\hline & $\begin{array}{c}\text { RF, d } 0 \\
(\mathrm{mg} / \mathrm{ml} \pm \text { SEM) }\end{array}$ & $\begin{array}{c}\text { RF, d } 30 \text {, } \\
\text { uninfected mice } \\
(\mathrm{mg} / \mathrm{ml} \pm \mathrm{SEM})\end{array}$ & $\begin{array}{c}\text { RF, d } 30 \text {, } \\
\text { infected mice } \\
(\mathrm{mg} / \mathrm{ml} \pm \mathrm{SEM})\end{array}$ \\
\hline Smi & $0.030 \pm 0.004(n=7)$ & & $0.044 \pm 0.008(n=7)^{\mathrm{A}}$ \\
\hline Smi $\times \operatorname{clgG}$ & $0.047 \pm 0.006(n=8)$ & & $0.145 \pm 0.018(n=8)^{\mathrm{B}}$ \\
\hline $\mathrm{Hul}$ & $0.102 \pm 0.015(n=6)$ & $0.357 \pm 0.118(n=5)^{\mathrm{B}, \mathrm{C}}$ & $0.844 \pm 0.128(n=6)^{\mathrm{A}, \mathrm{B}}$ \\
\hline $\mathrm{Hul} \times \operatorname{clg} \mathrm{G}$ & $0.103 \pm 0.013(n=10)$ & $0.479 \pm 0.060(n=7)^{\mathrm{B}}$ & $1.461 \pm 0.163(n=10)^{\mathrm{B}}$ \\
\hline
\end{tabular}

RF levels were measured by ELISA. ${ }^{A} P<0.05$ versus clgG knock-in; Mann-Whitney test.

${ }^{B} P<0.05$ versus day 0; Mann-Whitney test. ${ }^{C} N S$ versus clgG knock-in; Mann-Whitney test. 
A

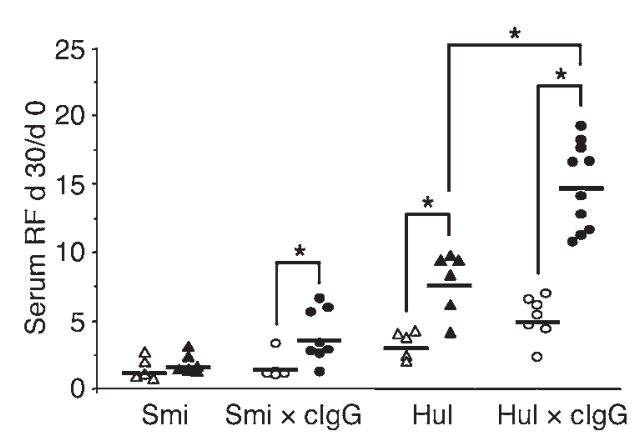

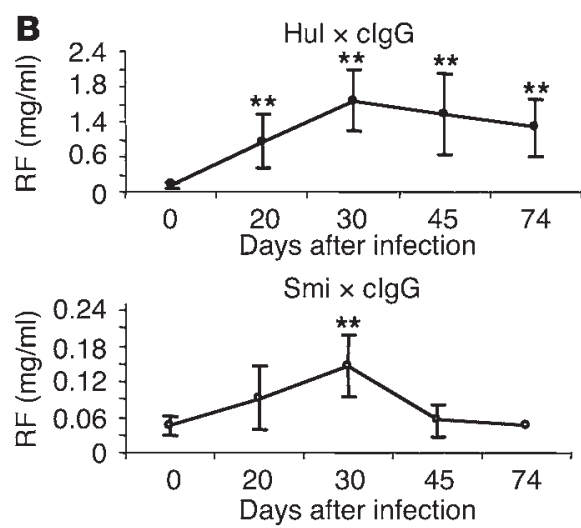

\section{Figure 3}

$B$. burgdorferi infection induces production of RF that is in part dependent on the presence of the autoantigen. (A) Ratios of serum RF levels between day 30 and day 0 in infected mice compared with controls. Each point represents an individual mouse and the relative level of RF at day 30 compared with the day 0 level. Open symbols, uninfected; filled symbols, infected. ${ }^{*} P<0.05$, Mann-Whitney test. (B) Kinetic of mean RF levels between day 0 and day of sacrifice in Hul $\times$ clgG infected mice, compared with Smi $\times$ clgG infected mice. ${ }^{* *} P<0.005$ compared with day 0 level, Mann-Whitney test.

and proliferated strongly in response to B. burgdorferi/anti-B. burgdorferi huIgG immune complexes, whereas $B$. burgdorferi or anti-B. burgdorferi huIgG alone, as well as B. burgdorferi preincubated with huIgG from healthy subjects (normal huIgG), produced little, if any, response (Figure 5A). RF B cell activation was autoantigen specific, since $\mathrm{IgMa}^{+} 17.109^{\text {low/- }} \mathrm{B}$ cells were not activated under the same conditions. Finally, sonicated B. burgdorferi stimulated RF production in vitro, whereas anti-B. burgdorferi huIgG alone did not. In accord with the proliferation data, B. burgdorferi/anti-B. burgdorferi huIgG immune complexes enhanced RF production by $30 \%$ compared with B. burgdorferi alone (Figure 5B).

This selective activation could reflect BCR signaling; alternatively, surface RF, by trapping immune complexes, may simply concentrate $B$. burgdorferi

splenocytes from these animals were stimulated in vitro with sonicated B. burgdorferi, purified huIgG from patients with high serum levels of anti-B. burgdorferi IgG (anti-B. burgdorferi huIgG), or immune complexes prepared by preincubation of these anti-B. burgdorferi huIgGs with sonicated B. burgdorferi. We also checked for the absence of anti-chromatin $\mathrm{Ab}$ in the patients' purified huIgG. All these reagents were toxin free. In the following experiments, sonicated B. burgdorferi was used at low concentration $(2.5 \mu \mathrm{g} / \mathrm{ml})$ to avoid masking the potential contribution of the huIgG. After 72 hours, we harvested the cells for flow cytometric analyses and collected the supernatants for measurements of IgM-RF by ELISA. RF B cells increased in size, upregulated CD86, particles on the $B$ cell membrane, thus enhancing TLR signaling. To distinguish between these hypotheses, we took advantage of the fact that the calcineurin antagonist cyclosporin A (CsA) is known to prevent the BCR cross-linking-induced activation of NFAT required for cellular proliferation without significantly altering TLR signaling, which does not involve any known calcium-calcineurin step (30). Purified Hul RF B cells were cultured as before in the presence or absence of CsA at $50 \mathrm{ng} / \mathrm{ml}$ (higher concentrations resulted in cellular toxicity). Consistent with our first hypothesis, CsA blocked the selective enhancement of Hul RF B cell proliferation induced by $B$. burgdorferi/IgG immune complexes without interfering with the proliferation induced by $B$. burgdorferi alone

\section{Figure 4}

Proliferation and activation of B cells in MyD88 wild-type (or MyD88+-) mice and MyD88deficient mice. (A) Purified $\mathrm{B}$ cells from MyD88 ${ }^{-/-}$or MyD88+/- mice on a C57BL/6 background were cultured for 72 hours in the presence or absence of sonicated $B$. burgdorferi $(10 \mu \mathrm{g} / \mathrm{ml})$. Histograms show divisions of CFSE-labeled B cells or surface expression of CD86 activation marker. Percentages indicate proliferating cells. (B) Splenocytes from Hul $\times$ clgG mice were cultured in the presence of different concentrations of sonicated $B$. burgdorferi. The percentage of proliferating cells was measured for each concentration after CFSE staining.
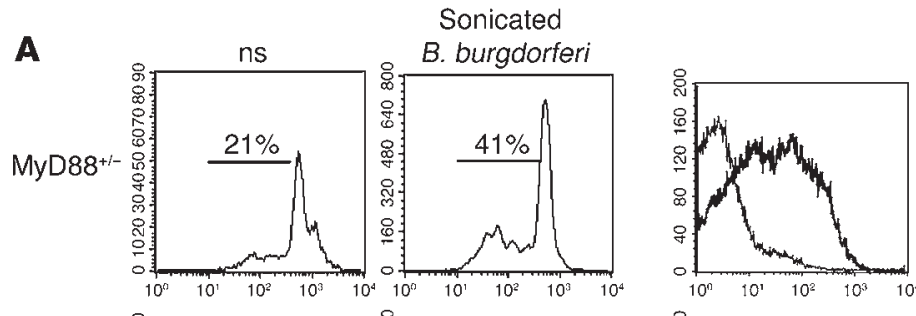

- Unstimulated
- Sonicated
B. burgdorferi
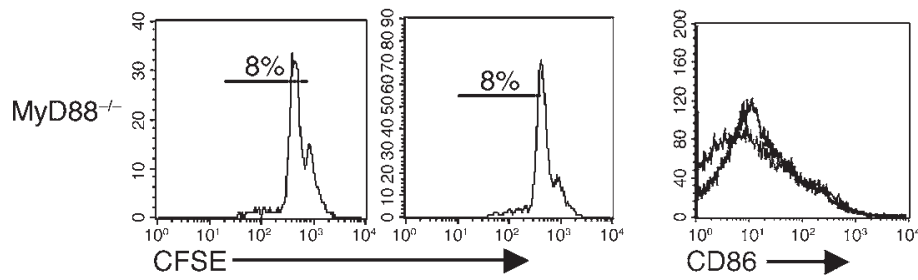

B

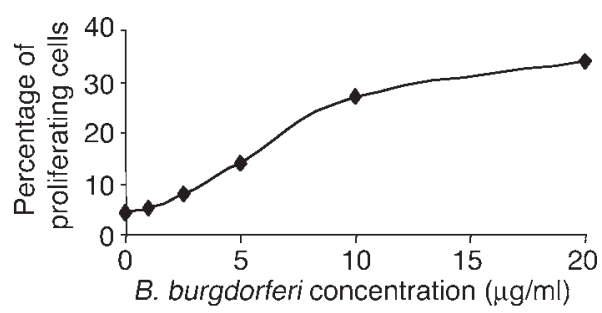


A ns

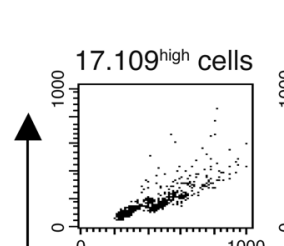

$17.109^{\text {low/- }}$ cells

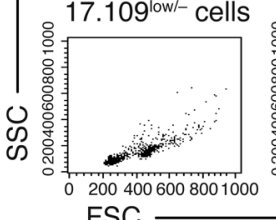

FSC
Anti-

B. burgdorferi hulgG
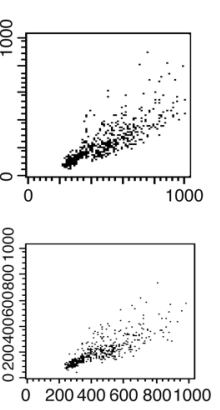

$17.109^{\text {high }}$ cells

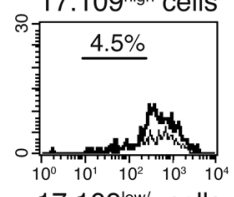

$17.109^{\text {low/ }}$ cells

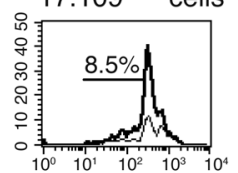

CFSE

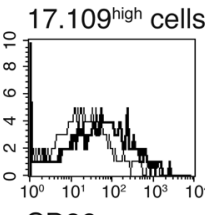

CD86
Anti-

B. burgdorferi hulgG
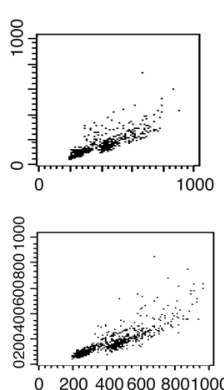

02004006008001000
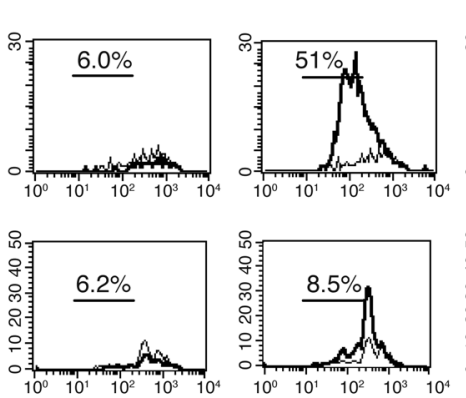
B. burgdorferi + anti-
B. burgdorferi

hulgG
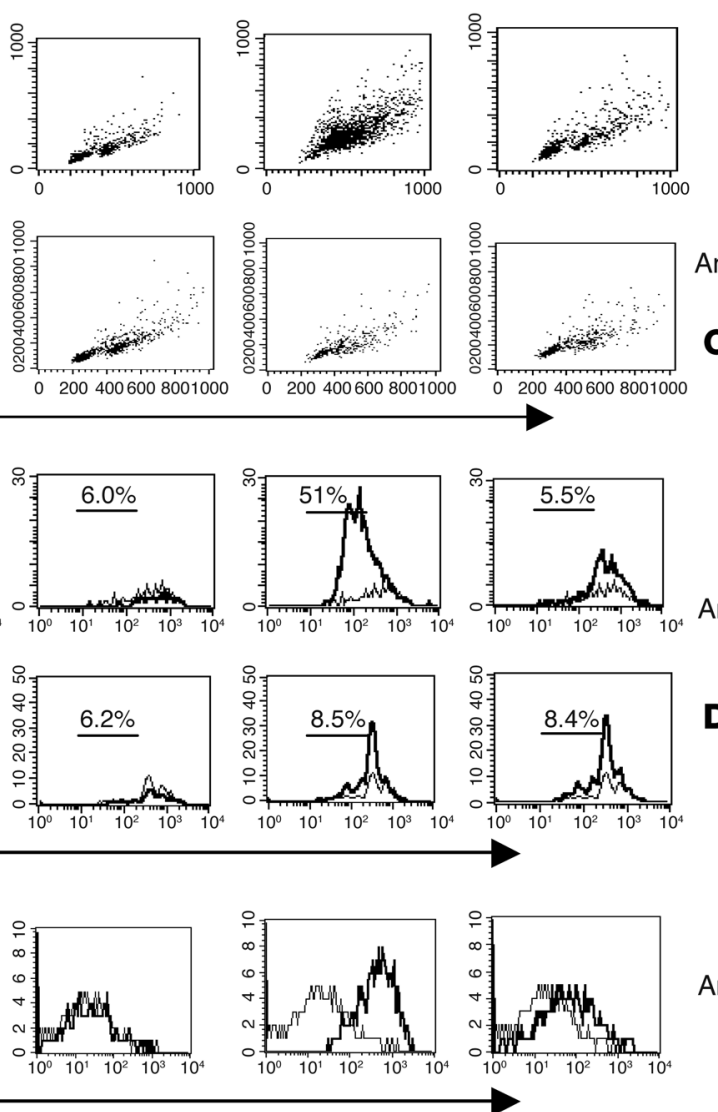

D

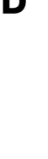

B + normal + normal
hulgG

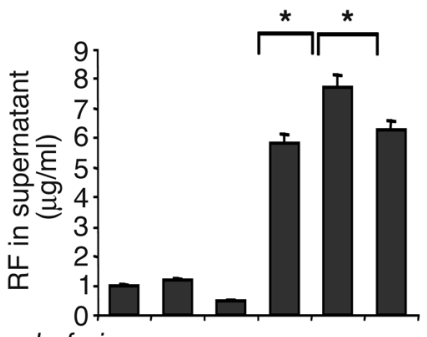

B. burgdorferi -

$\begin{array}{llllll}\text { B. burgdorferi - } & - & - & + & + & + \\ \text { Normal hulgG }- & + & - & - & - & +\end{array}$ hulgG

\section{C}
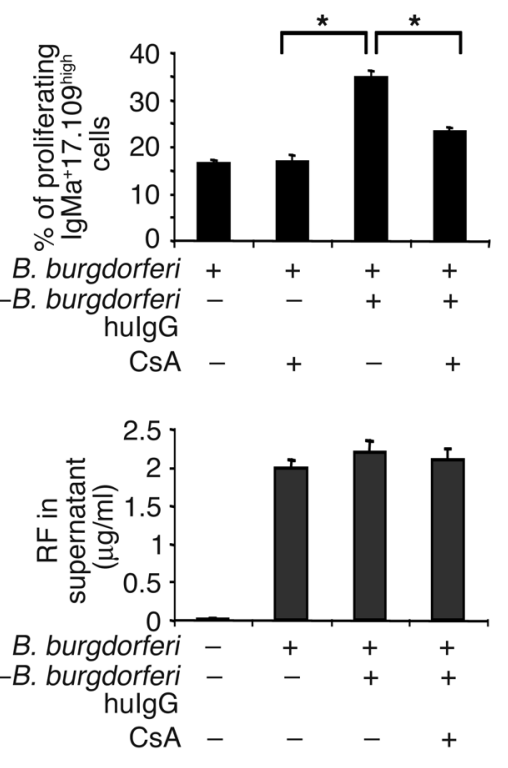

Figure 5

Proliferation and activation of RF B cells in response to $B$. burgdorferi are increased in the presence of $B$. burgdorferi/lgG complexes. (A and B) Splenocytes of Hul Tg mice were cultured with suboptimal concentrations $(2.5 \mu \mathrm{g} / \mathrm{ml})$ of sonicated $B$. burgdorferi, purified human anti-B. burgdorferi hulgG $(1 \mathrm{mg} / \mathrm{ml})$, a mixed solution containing $B$. burgdorferi and purified anti-B. burgdorferi hulgG, or a mixed solution containing $B$. burgdorferi and nonspecific hulgG (normal hulgG). (A) Side scatter versus forward scatter plots were used to monitor cell size of 17.109high or $17.109^{\mathrm{low} /-}$ B cells (top 2 rows). The next 2 rows of histograms show divisions of CFSE-labeled 17.109high or 17.109low/- B cells; percentages indicate proliferating cells. The bottom row of histograms shows surface expression of CD86 on 17.109 high B cells. Thick lines represent the stimulated B cells, and thin lines the nonstimulated B cells. Results shown are representative of 4 separate experiments. Acquisition parameters were determined to analyze at least $2 \times 10^{3}$ cells in the $17.109^{\text {high }}$ or $17.109^{\text {low/ }}-\mathrm{B}$ cell gates (total numbers of cells: $4 \times 10^{4}$ to $2 \times 10^{6}$ ). (B) RF supernatant production was measured at day 3 . Values \pm 1 SEM are shown. ${ }^{\star} P<0.05$. (C and $\mathbf{D}$ ) Purified splenic $B$ cells of Hul Tg mice were cultured as in A. (C) CsA (50 ng/ml) was added at culture initiation. Values \pm SEM represent the percentage of proliferating lgMa ${ }^{+17.109 \text { high }}$ cells in the different conditions of stimulation. ${ }^{*} P<0.05$. (D) RF supernatant production \pm SEM was measured at day 3.

(Figure 5C). Since for these experiments we used purified B lymphocytes, the data also show that both BCR-dependent and BCRindependent RF B cell-induced proliferations did not require other cells - in particular, T cells. However, a different pattern comes to light when autoantibody production is examined. Indeed, anti- $B$. burgdorferi immune complexes were no more able to increase the RF secretion induced by B. burgdorferi alone (Figure 5D). This suggests that the Ab secretion component of the RF B cell activation induced by B. burgdorferi/huIgG complexes may depend on the presence of other cells, Th cells being obvious candidates.

Among autoreactive B cells, RF B cells have the noteworthy property of recognizing an autoantigen of which the main biological role is to bind foreign antigens. It has been shown in vitro that RF B cells are able to capture foreign antigens in immune complex form and to activate specific T cells (31). However, the relevance of this mechanism in vivo is unknown. To investigate the role of $\mathrm{T}$ cells in the breakdown of $\mathrm{Tg}$ RF B cell tolerance, we treated Hul and Hul $\times$ cIgG mice 2 days before the infectious challenge with a nondepleting anti-CD4 mAb under conditions demonstrated to completely coat and block CD $4^{+} \mathrm{T}$ cells for 4 weeks (32). Animals were sacrificed 30 days after infection and analyzed as above. There was no significant difference in the B cell phenotypes between these animals and the immunocompetent ones (not shown); in particular, B. burgdorferi infection resulted in a comparable increase of the LN B cell compartments (roughly 4-fold). Likewise, serum RF levels were still increased in Hul infected animals compared with healthy animals, which is consistent with the fact that B. burgdorferi is directly mitogenic for B cells in 


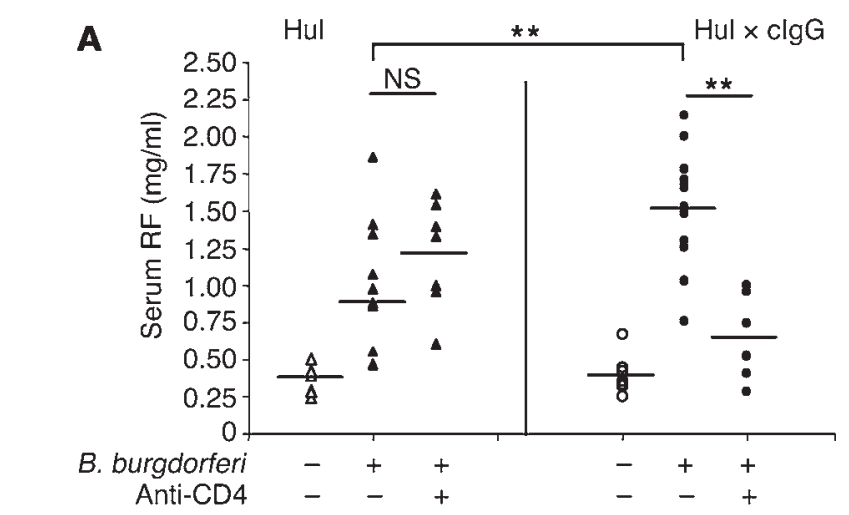

$\mathbf{B}$

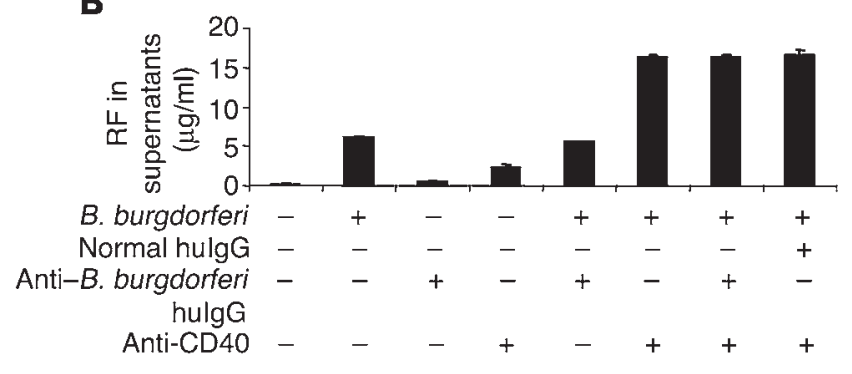

vitro (Figure 6A). However, most interestingly, CD4 T cell blockage completely abolished the autoantigen-dependent enhanced production of serum RF in infected $\mathrm{Hul} \times \mathrm{cIgG}$ mice.

Depending on the system, the $\mathrm{T}$ cell help can be mediated by the interaction of CD40 ligand (CD154) with CD40 that is constitutively expressed by B cells, and/or by secreted ILs. Because syngeneic B. burgdorferi-specific T cell clones were not available, we evaluated the contribution of CD40 signaling using a stimulating anti-CD40 Ab. Purified B cells from Hul Tg mice were cultured with sonicated B. burgdorferi, anti-B. burgdorferi huIgG, or B. burgdorferi/anti-B. burgdorferi huIgG immune complexes in the presence or absence of activating anti-CD40 Ab (Figure 6B). Anti-CD40 $\mathrm{Ab}$ clearly promoted RF secretion induced by $B$. burgdorferi alone. This indicates that concurrent TLR stimulation by B. burgdorferi is synergistic with CD40 signaling to induce B lymphocyte differentiation into Ab-secreting cells. Such a costimulation was not observed for B cells from MyD88-/- mice (data not shown). In these experiments anti-B. burgdorferi huIgG immune complexes were not more potent than B. burgdorferi alone nor than B. burgdorferi preincubated with normal huIgG to induce RF production. This could be due to culture conditions; alternatively, it could indicate that the main role of the BCR in the autoantigen-specific activation of RF B cells is to deliver B. burgdorferi antigens to specific T cells.

\section{Discussion}

Overall, the data presented herein show that, during a chronic bacterial infection, innate immunity receptors (most probably TLRs), the autoantigen, and CD4 T cells cooperate to break the immunological ignorance of RF B cells in mice that are not genetically prone to develop autoimmune diseases (see Figure 7 for a summary of the mechanisms potentially involved).

In humans, infectious diseases with a wide variety of pathogens, as diverse as subacute bacterial endocarditis, tuberculosis, and type $C$ viral hepatitis, are frequently associated with a high production of RFs (12). The mechanism of this production is usually con-

\section{Figure 6}

clgG-dependent RF production in Hul $\times$ clgG Tg mice requires $\mathrm{T}$ cell help. (A) Transgenics were treated by several i.p. injections of the anti-CD4 mAb YTS177 to block CD4+ cells for at least 4 weeks (see Methods). Each point represents the serum RF level in a single mouse. The infected and treated mice are compared with infected and untreated mice. Uninfected mice are shown as controls. Differences between $\mathrm{Hul} \times \mathrm{clgG}$ infected treated and untreated mice are significant $(P<0.05$, MannWhitney test), whereas differences between Hul infected treated and untreated mice are not (NS). Differences between Hul infected and $\mathrm{Hul} \times \mathrm{clgG}$ infected treated and untreated mice are significant ${ }^{* \star} P<0.05$, Mann-Whitney test). (B) Purified splenic B cells of Hul Tg mice were cultured for 6 days in the same conditions as in Figure 5A. Anti-CD40 agonist $(10 \mu \mathrm{g} / \mathrm{ml})$ was added beforehand to mimic $T$ cell help. RF production \pm SEM was measured at day 6 in the supernatants.

sidered to be nonspecific, i.e., irrespective of the BCR specificity. Indeed, our results show that autoantigen-ignorant Tg RF B cells proliferate like other B cells and that RFs participate in the resulting hypergammaglobulinemia. However, RF production is substantially higher and is more sustained in $\mathrm{Hul} \times \mathrm{cIgG}$ compared with the other Tg lines (low-affinity RF, and Hul), which shows that an autoantigen-induced step constitutes a second mechanism involved in RF production.

The mechanisms underlying nonspecific B cell activation during infectious states have long been studied, although many issues remain unclear $(1,2,4,5-7,9,33)$. There is convincing evidence that these mechanisms are numerous, including direct activation by $\mathrm{B}$ cell mitogens; cytokines released from activated $T$ cells, which may substitute nonspecifically for Th cells; or even T cell help that occurs through cognate interaction but is independent of BCR specificity (7). Regarding B. burgdorferi infection, activation of B cells through

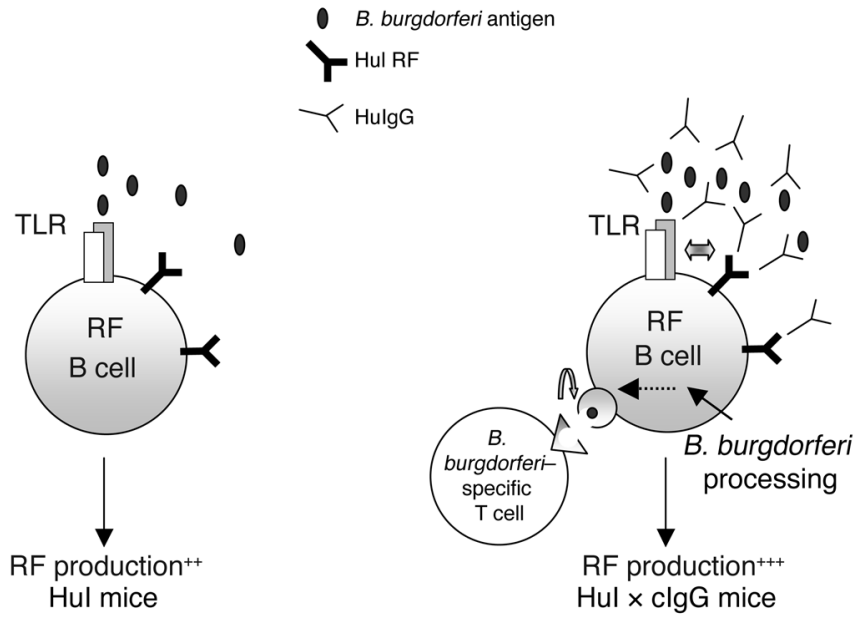

Figure 7

A possible mechanism for the activation of RF-expressing Hul B cells in $\mathrm{Hul} \times$ clgG mice by immune complexes containing anti-B. burgdorferi IgG and $B$. burgdorferi antigens. In the left panel, B cells as well as RF $B$ cells are stimulated by $B$. burgdorferi through TLR interaction. In the right panel, the presence of anti-B. burgdorferi hulgG in $\mathrm{Hul} \times$ clgG mice induces the formation of $B$. burgdorferi-containing immune complexes, which are able to cosignal through TLR and RF-BCR. $B$. burgdorferi is processed into antigenic peptides in RF B cells after internalization; $B$. burgdorferi-specific $T$ cells cooperate to increase RF production. ++ and +++ refer to the intensity of RF production. 
TLRs certainly plays an important role. B. burgdorferi lipoproteins including OspA and OspB possess potent B cell mitogenic properties capable of stimulating polyclonal proliferation and Ig production in vitro $(21,25-27)$. These properties are dependent on the $\mathrm{Pam}_{3} \mathrm{Cys}$ modification of lipoproteins and involve TLRs, particularly TLR2. Here we have shown that the proliferation of B cells from wild-type mice induced by B. burgdorferi in vitro is completely abolished for cells from MyD88-deficient mice. In addition, the experiments depicted in Figure 4A and Figure 5C clearly demonstrate that purified murine B cells can be directly stimulated by B. burgdorferi, even though the participation in vivo of other cells expressing TLRs and/or of other pathogen-associated molecular pattern (PAMP) receptors is likely. Still, the process is not dependent on CD4 T cells, since their blockade does not reduce the production of RFs in Hul infected mice.

The second, autoantigen-induced, step is illustrated by the increased RF production in $\mathrm{Hul} \times \mathrm{cIgG}$ mice compared with $\mathrm{Hul}$ animals. The results in vivo are underpinned by in vitro experiments. Immune complexes made of anti-B. burgdorferi huIgG and sonicated $B$. burgdorferi greatly enhance the activation and proliferation of RF B cells as well as the secretion of RF compared with those induced by B. burgdorferi alone. This phenomenon is autoantigen-specific, since it is not observable for nonRF IgMa $17.109^{\text {low } /-}$ B cells. As expected from previous data (15), anti-B. burgdorferi huIgG alone had no effect. While CsA treatment did not interfere with $B$. burgdorferi-induced proliferation, it blocked the enhancement of proliferation induced by the immune complexes, which strongly support BCR signaling. This phenomenon could find its biological significance in a possible role as an amplifier of immune responses, which is suspected for RF B cells. Indeed, Roosnek and Lanzavecchia have shown in vitro that RF B cells can capture exogenous antigens in immune complex form, process them, and present antigenic peptides to specific CD4 T cells (31). These T cells could then induce RF B cells to secrete through cognate interactions. In accord with this hypothesis, we show that CD4 $\mathrm{T}$ cell blockade in vivo had no effect on the nonspecific part of the RF B cell activation, since serum RFs were similar between anti-CD4-treated and untreated Hul infected mice. However, CD4 T cell blockade completely suppressed the autoantigendependent RF production in Hul $\times$ cIgG mice. To be precise, CD4 $\mathrm{T}$ cells seem dispensable for the proliferation component of the selective activation mediated by anti-B. burgdorferi immune complexes, since it was still observed with purified B cells and since $\operatorname{IgMa}^{+} 17.109^{+}$cell numbers were increased in similar proportions in anti-CD4-treated and untreated mice. However, their presence is critical for the autoantigen-induced secretion of RF. With current knowledge, the most straightforward explanation is that RF $B$ cells, having captured B. burgdorferi antigens in immune complex form, receive $\mathrm{T}$ cell help through a cognate interaction with antiB. burgdorferi-specific T cells, which allows them to differentiate into plasma cells. Alternatively, secondary to TLR/BCR costimulation, B cells may be able to differentiate following noncognate interaction with activated CD4 $\mathrm{T}$ cells or with cytokines produced by them. Distinguishing between these hypotheses is at present hampered by the lack of available B. burgdorferi-specific CD 4 T cell clones. A limitation of our study is the impossibility to provide direct evidence for the involvement of immune complexes in vivo.

From an autoimmunity point of view, several points merit further attention. First, it has been shown that in vivo bacterial infectious disease can activate not only low-affinity autoreactive B cells, but also higher-affinity anti-self B cells that have escaped cen- tral or peripheral tolerance. These last cells are known to exist in humans during chronic infection with mycobacteria (34), but also in healthy individuals $(10,35)$, maybe as a consequence of repeated benign infections. Whether autoreactive $B$ cell activation by this process can lead to affinity maturation remains an open question. Somatic hypermutation is usually poorly effective in regular $\mathrm{Ab}$ $\mathrm{Tg}$ systems on non-autoimmune-prone genetic backgrounds; therefore it is probable that it cannot be readily studied with our current models. However, efficient antigen-driven somatic hypermutation is usually dependent on the availability of T cell help, which is shown here to occur in the second, autoantigen-induced, step of RF B cell activation.

Second, in view of the recent data from Marshak-Rothstein's and Goodnow's groups $(29,30)$, it is reasonable to assume that Hul RF B cells are activated through a 2-signal mechanism involving concurrent stimulations of the BCR and some PAMP receptor, most probably TLR, pathways. The direct demonstration of this hypothesis and the identification of the involved receptors will necessitate the generation of RF $\mathrm{Tg}$ backcrosses to appropriate $\mathrm{KO}$ mice. Rui et al. have demonstrated in the anti-hen-egg lysozyme (anti-HEL) model that stimulation with antigen is synergistic with CPG DNA through TLR9 signaling (30), and Leadbetter et al. have shown that mammalian chromatin-containing IgG immune complexes induce the proliferation of AM14 RF B cells in vitro and have provided strong evidence that this phenomenon results from the sequential engagement of the BCR and TLR9 (29). In our model, TLR9 is probably not similarly involved, since infected mouse serum and purified huIgG enriched in anti-B. burgdorferi huIgG were devoid of antichromatin Abs. This theory was recently questioned by Rui et al., who showed in vitro that autoreactive B cells that were anergized by the constitutive presence of the autoantigen could not be induced to produce autoantibodies by activation of the TLR pathway (30). Our data suggest that there is a window of BCR affinities that allow autoreactive B cells to evade classical tolerance mechanisms and to appear ignorant but that permit their activation by the autoantigen when a second signal is provided. We think that our results extend the BCR/TLR9 coengagement paradigm and further support a role for this mechanism as a link between infection and autoimmunity.

Third, the next question is whether any autoreactive B cells can be activated by this mechanism provided that self antigen is accessible to the BCR. Recently, Viglianti et al. have extended the BCR/TLR9 coengagement to DNA-reactive B cells (36). However, an important result from our in vitro experiments is that normal huIgG (i.e., devoid of anti-B. burgdorferi Abs) are unable to increase the activation of Hul RF B cells induced by B. burgdorferi. This suggests that a physical interaction or a cross-link between the TLR and the BCR may be required. Since TLR9 is not expressed at the B cell membrane, this could occur at the membrane of the TLR9-associated subcellular compartment after internalization of the BCR complexed with DNA fragments. If such a limitation proved to be true, it could, together with the high frequencies of RF and anti-nuclear Abs expressing B cells in the naive repertoire, account for the fact that these autoantibodies are the most frequent produced during infectious diseases. However, the results obtained in the CPG DNA anti-HEL model are more difficult to account for. One possibility could be that HEL binds to CPG DNA through charge-based interactions (30). Clearly this question needs further investigation. 
Finally, further studies will be required to first determine the mechanism that controls the occurrence of pathogenic autoantibodies in individuals recurrently exposed to infectious diseases, and second, to determine what differentiates these individuals from patients suffering from autoimmune disease.

\section{Methods}

Mice. All mouse lines were housed and crossed in isolator cages at the animal facility of the Centre de recherche d'immunologie et d'hématologie (Hôpital Civil). B. burgdorferi-inoculated mice and the uninfected controls were housed in the animal facility at the Laboratoire de bactériologie (Hôpitaux universitaires de Strasbourg). C57BL/6 and $\mathrm{C} 3 \mathrm{H} / \mathrm{Hej}$ mice were bought from Harlan France SARL. MyD88deficient mice (MyD88 KO, or MyD88 ${ }^{-/}$) on a C57BL/6 background were bought from the Centre de Distribution, de Typage et d'Archivage (Orleans, France) animal laboratories. All animal experiments were performed with approval by the Direction départementale des services vétérinaires (Strasbourg, France).

The generation of Smi, Smi $\times$ cIgG, Hul, and Hul $\times$ cIgG mice has been previously described (13-15). Briefly, RF transgenics are generated as single-chain transgenics ( $\mathrm{H}$ or L) on a C57BL/6 background. Singlechain transgenics are crossed with cIgG knock-in mice generated on a mixed background (at least 6 backcrosses with C57BL/ 6 mice) and then intercrossed to obtain Smi, Smi $\times$ cIgG, Hul, and Hul $\times$ cIgG mice on the same genetic background. For experiments, Tg mice were always compared with their littermate controls. The cIgG knock-in line was kindly provided by K. Rajewsky (CBR Institute for Biochemical Research, Harvard Medical School, Boston, Massachusetts, USA) and expressed cIgG with human $\gamma$ chain $\mathrm{C} 1$ region.

Screening of the transgenics was performed as previously described (13). Smi and Hul transgenics were identified after tail DNA PCR typing, and cIgG knock-in mice were selected by ELISA (huIgG dosage; ref. 17).

$\mathrm{MyD}^{+/-}$mice were obtained by backcrossing of MyD88 KO mice with C57BL/6 mice.

B. burgdorferi infection. The B. burgdorferi sensu stricto $\mathrm{cN} 40$ isolate was cultivated at low passage in Barbour-Stoenner-Kelly medium (BSK-H medium; Sigma-Aldrich) supplemented with $6 \%$ normal rabbit serum (SigmaAldrich) at $33^{\circ} \mathrm{C}$. Four-week-old mice were infected with $10^{6}$ spirochetes by intradermal injection of $0.1 \mathrm{ml}$ in the shaved back. Control mice were injected with an equal volume of sterile BSK-H medium and housed in the same conditions as infected animals. Mice were killed at intervals of 2-8 weeks after inoculation. The infectious status of the animals was determined at sacrifice by culture of different specimens (bladder, ear, heart, spleen) in 7-ml tubes of BSK-H medium for up to 4 weeks at $33^{\circ} \mathrm{C}$. Considering 100 infected animals, culture of at least 1 organ was positive for 90 . Only the animals with a positive culture were included in our analysis.

Flow cytometry. Preparation of LNs and spleen cell suspensions and their staining for flow cytometry have been already described (13). The analysis of the $\mathrm{B}$ cell phenotype was performed by double or triple staining with anti-B220 $0_{\mathrm{FITC}}$, anti-IgMa biotin, $_{\text {anti-IgM }}$ PE, CD21 $1_{\mathrm{FITC}}$, CD23 $3_{\mathrm{PE}}$ (BD Biosciences - Pharmingen), and $17.109_{\text {biotin }}$; 7.109 recognizes the Tg RF VK chain idiotype and was provided by D.A. Carson (University of San Diego, San Diego, California, USA). The expression analysis of the activation marker CD86 was performed using anti-CD86 $6_{\mathrm{PE}}$ (BD Biosciences - Pharmingen). Viable cells were identified by incorporation of propidium iodide $(5 \mathrm{mg} / \mathrm{ml})$. The analysis was performed with a FACSCalibur using the CellQuest software package (BD Biosciences).

ELISA. ELISA assays for serum IgM and serum chimeric RF were done as previously described $(13,15)$. Binding of total IgM was determined by addition of a peroxidase-coupled anti-mouse IgM (Jackson ImmunoResearch
Laboratories Inc.). For RF dosage, plates were coated with anti-IgMa (Smi and Smi $\times \operatorname{cIgG}$ mice) or the mAb H1.10 (Hul and Hul $\times$ cIgG mice), and serum RF concentrations were revealed by addition of biotin-labeled 17.109 $\mathrm{Ab}$ and then steptavidin-peroxidase. The $\mathrm{H} 1.10 \mathrm{mAb}$ recognizes the Tg Hul RF VH chain idiotype and was provided by D.A. Carson.

For murine RF, plates were coated with total murine IgG $(50 \mu \mathrm{g} / \mathrm{ml}$; Jackson ImmunoResearch Laboratories Inc.), and serum RF concentrations were revealed by addition of a peroxidase-coupled anti-mouse IgM.

Mouse sera were tested for human and murine IgG Abs against B. burgdorferi using a modified commercial kit (Enzygnost Borreliosis IgG kit; Dade Behring Inc.). To detect murine IgG against B. burgdorferi, the antihuman conjugate was replaced by a peroxidase-conjugated $\mathrm{F}\left(\mathrm{ab}^{\prime}\right)_{2}$ goat anti-mouse IgG diluted to 1:50,000 (Jackson ImmunoResearch Laboratories Inc.). The other steps of the protocol were as described by the manufacturer. Sera were considered positive when OD values reached the OD of pooled uninfected mice plus $3 \mathrm{SD}$.

Mouse sera were tested for huIgG Abs against chromatin using a commercial kit (QUANTA Lite chromatin kit; INOVA Diagnostics Inc.). The subsequent steps of the test were performed as described previously (37). As positive controls, the positive standard serum included in the kit and a positive patient's serum were used.

$B$ cell proliferation assays. Spleens or LNs were removed from $\mathrm{Tg}$ mice,

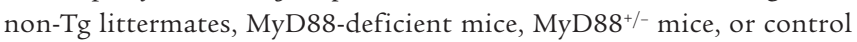
C57BL/6 mice and teased apart. Cells were washed and resuspended in RPMI 1640 with L-glutamine (BioWhittaker Inc.) supplemented with gentamicin (40 $\mu \mathrm{g} / \mathrm{ml}$; BioWhittaker Inc.), 2-mercaptoethanol (50 $\mu \mathrm{M}$; Sigma-Aldrich), and $10 \%$ heat-inactivated FCS (Dominique Dutscher). Cells $\left(1.10^{6}\right.$ per milliliter) were incubated in 24 -well BD Falcon plates (in a total volume of $1,000 \mu \mathrm{l}$ ) with $10 \mu \mathrm{g} / \mathrm{ml}$ LPS from Salmonella typhi (SigmaAldrich), $10 \mu \mathrm{g} / \mathrm{ml}$ of a F( $\left.\mathrm{ab}^{\prime}\right)_{2}$ goat anti-mouse IgM (Jackson ImmunoResearch Laboratories Inc.), $1 \mathrm{mg} / \mathrm{ml}$ of aggregated huIgG (Sandoglobuline; Novartis Pharma), $2.5-10 \mu \mathrm{g} / \mathrm{ml}$ of sonicated B. burgdorferi, $1 \mathrm{mg} / \mathrm{ml}$ purified huIgG from healthy individuals or B. burgdorferi-infected patients, or mixed solution containing B. burgdorferi $(2.5 \mu \mathrm{g} / \mathrm{ml})$ and huIgG $(1 \mathrm{mg} / \mathrm{ml})$, in the presence or absence of $10 \mu \mathrm{g} / \mathrm{ml}$ anti-CD40 agonist (BD Biosciences - Pharmingen) or $50 \mathrm{ng} / \mathrm{ml} \mathrm{CsA} \mathrm{(Novartis} \mathrm{Pharma).} \mathrm{Aggregated} \mathrm{huIgGs}$ were prepared by heating at $65^{\circ} \mathrm{C}$ for 15 minutes.

After $60-72$ hours of culture at $37^{\circ} \mathrm{C}$, the phenotype of the cells was determined by flow cytometry analysis.

For proliferation assays, cells were labeled with CFSE (Invitrogen Corp.) before addition of LPS, anti-IgM, or B. burgdorferi with or without huIgG. Suspensions of $2.10^{7}$ cells per milliliter in $0.1 \%$ PBS/BSA were incubated with CFSE at a final concentration of $2 \mu \mathrm{M}$ for 10 minutes at $37^{\circ} \mathrm{C}$. Cells were then washed and resuspended in the culture medium.

For CD86 expression, the cells were labeled after 60-72 hours of culture, as described in "Flow cytometry."

Preparation of B. burgdorferi/buIgG complexes. Sonicated B. burgdorferi was prepared as follows. B. burgdorferi sensu stricto $\mathrm{cN} 40$ was grown at $33^{\circ} \mathrm{C}$ in ten $7-\mathrm{ml}$ tubes of BSK-H medium and harvested after 5 days of culture. The cell pellet was washed 3 times with cold $\mathrm{PBS}$ and $0.1 \% \mathrm{MgCl}_{2}$ ( $\mathrm{pH}$ 7.2). The final pellet was resuspended in $1 \mathrm{ml}$ of Tris- $\mathrm{HCl}, 0.5 \mathrm{M}$ (pH 8), and $2 \mathrm{ml}$ of Laemmli buffer (Bio-Rad Laboratories) and denaturated by heating at $95^{\circ} \mathrm{C}$ for 3 minutes. The protein content of this preparation was determined by Lowry assay.

To purify huIgG, pooled sera from infected patients or controls (IgG anti-B. burgdorferi titers between 500 and $1,000 \mathrm{U}$ as determined by the Enzygnost Borreliosis IgG kit; Dade Behring Inc.) were cleared by centrifugation and decomplemented. Each pool of serum was then loaded onto a DEAE Affi-Gel Blue Gel column (Bio-Rad Laboratories) according to the manufacturer's instructions. Eluted fractions were concentrated and switched to PBS buffer using Stir Cel Omega 30K (Pall Corp.). IgG titers 
were measured by ELISA. IgG solutions were then tested for endotoxins (PYROGENT Plus Cel Clot Assay; Cambrex Corp.).

Immune complexes comprising B. burgdorferi and huIgG were made by premixing of $B$. burgdorferi solution with IgG at room temperature for 120 minutes, before addition to the assay.

B lymphocyte purification (magnetic cell separation). Splenic B cells were isolated with a magnetic cell separation (MACS) depletion protocol (Miltenyi Biotec). Splenocyte samples were depleted of non-B cells with anti-CD43 magnetic beads (Miltenyi Biotec). The purity of the B cell fractions was greater than $80 \%$.

Anti-CD4treatment. Nondepleting mouse anti-CD4Abs(YTS177.9.6.1; ref.38) in ascite form diluted in PBS (50 $\mu \mathrm{l}$ ascite plus $50 \mu \mathrm{l}$ PBS per mouse per injection) were administered i.p. 2 days before B. burgdorferi infection, and then twice a week until sacrifice. Control animals were injected with PBS.

\section{Acknowledgments}

We thank S. Muller and F. Monneaux for help with murine and human anti-chromatin IgG ELISAs. This work was supported by grants from INSERM, Association pour la Recherche sur la Polyarthrite, and Strasbourg Louis Pasteur University.

Received for publication February 3, 2005, and accepted in revised form May 24, 2005.

Address correspondence to: Thierry Martin, Laboratoire d'Immuno pathologie, INSERM EMI 0222, Centre de recherche d'immunologie et d'hématologie, Hôpital Civil, 1 place de l'hôpital, 67091 Strasbourg Cedex, France. Phone: 33-390-24-39-83; Fax: 33-39024-40-16; E-mail: Thierry.martin@chru-strasbourg.fr.
1. Bach, J.F. 2002. The effect of infections on susceptibility to autoimmune and allergic diseases. N. Engl. J. Med. 347:911-920.

2. Wucherpfennig, K.W. 2001. Mechanisms for the induction of autoimmunity by infectious agents. J. Clin. Invest. 108:1097-1104. doi:10.1172/ JCI200114235.

3. Benoist, C., and Mathis, D. 2001. Autoimmunity provoked by infection: how good is the case for $\mathrm{T}$ cell epitope mimicry [review]? Nat. Immunol. 2:797-801.

4. Sangster, M.Y., et al. 2000. Analysis of the virus-specific and nonspecific B cell response to a persistent B-lymphotropic gammaherpesvirus. J. Immunol. 164:1820-1828.

5. Oldstone, M.B., and Dixon, F.J. 1969. Pathogenesis of chronic disease associated with persistent lymphocytic choriomeningitis viral infection. I. Relationship of antibody production to disease in neonatally infected mice. J. Exp. Med. 129:483-505.

6. Coutelier, J.P., Coulie, P.G., Wauters, P., Heremans, H., and Logt, J.T. 1990. In vivo polyclonal B-lymphocyte activation elicited by murine viruses J. Virol. 64:5383-5388.

7. Hunziker, L., et al. 2003. Hypergammaglobulinemia and autoantibody induction mechanisms in viral infections. Nat. Immunol. 4:343-349.

8. Yang, L., et al. 1992. Evidence for B-lymphocyte mitogen activity in Borrelia burgdorferi-infected mice. Infect. Immun. 60:3033-3041.

9. Silverstein, A.M., and Rose, N.R. 2003. On the implications of polyclonal B cell activation. Nat. Immunol. 4:931-932.

10. Lieby, P., et al. 2003. Memory B cells producing somatically mutated antiphospholipid antibodies are present in healthy individuals. Blood. 102:2459-2465.

11. Schettino, E.W., Chai, S.K., Kasaian, M.T., Schroeder, H.W., and Casali, P. 1997. VHDJH gene sequences and antigen reactivity of monoclonal antibodies produced by human B-1 cells. J. Immunol. 158:2477-2489.

12. Dorner, T., Egerer, K., Feist, E., and Burmester, G.R. 2004. Rheumatoid factor revisited. Curr. Opin. Rheumatol. 16:246-253.

13. Koenig-Marrony, S., et al. 2001. Natural autoreactive B cells in transgenic mice reproduce an apparent paradox to the clonal tolerance theory. J. Immunol. 166:1463-1470.

14. Julien, S., Soulas, P., Garaud, J.C., Martin, T., and Pasquali, J.L. 2002. B cell positive selection by soluble self-antigen. J. Immunol. 169:4198-4204.

15. Soulas, P., et al. 2002. A role for membrane IgD in the tolerance of pathological human rheumatoid factor B cells. Eur. J. Immunol. 32:2623-2634.

16. Wooten, R.M., and Weis, J.J. 2001. Host-pathogen interactions promoting inflammatory Lyme arthritis: use of mouse models for dissection of disease processes [review]. Curr. Opin. Microbiol. 4:274-279.

17. Zou, Y.R., Muller, W., Gu, H., and Rajewsky, K. 1994. Cre-loxP-mediated gene replacement: a mouse strain producing humanized antibodies. Curr. Biol. 4:1099-1103.

18. Barthold, S.W., Beck, D.S., Hansen, G.M., Terwilliger, G.A., and Moody, K.D. 1990. Lyme borreliosis in selected strains and ages of laboratory mice. J. Infect. Dis. 162:133-138.

19. McKisic, M.D., and Barthold, S.W. 2000. T-cellindependent responses to Borrelia burgdorferi are critical for protective immunity and resolution of Lyme disease. Infect. Immun. 68:5190-5197.

20. Liang, F.T., Nelson, F.K., and Fikrig, E. 2002. Molecular adaptation of Borrelia burgdorferi in the murine host. J. Exp. Med. 196:275-280.

21. Wooten, R.M., et al. 2002. Toll-like receptor 2 is required for innate, but not acquired, host defense to Borrelia burgdorferi. J. Immunol. 168:348-355.

22. Yang, L., et al. 1992. Evidence for B-lymphocyte mitogen activity in Borrelia burgdorferi-infected mice. Infect. Immun. 60:3033-3041.

23. Ma, Y., and Weis, J.J. 1993. Borrelia burgdorferi outer surface lipoproteins OspA and OspB possess B-cell mitogenic and cytokine-stimulatory properties. Infect. Immun. 61:3843-3853.

24. Anguita, J., et al. 1997. B7-1 and B7-2 monoclonal antibodies modulate the severity of murine Lyme arthritis. Infect. Immun. 65:3037-3041.

25. Bolz, D.D., et al. 2004. MyD88 plays a unique role in host defense but not arthritis development in Lyme disease. J. Immunol. 173:2003-2010.

26. Alexopoulou, L., et al. 2002. Hyporesponsiveness to vaccination with Borrelia burgdorferi OspA in humans and in TLR1- and TLR2-deficient mice.
Nat. Med. 8:878-884.

27. Takeuchi, O., et al. 2002. Cutting edge: role of Tolllike receptor 1 in mediating immune response to microbial lipoproteins. J. Immunol. 169:1-14

28. Akira, S., and Takeda, K. 2004. Toll-like receptor signalling [review]. Nat. Rev. Immunol. 4:499-511.

29. Leadbetter, E.A., et al. 2002. Chromatin-IgG complexes activate B cells by dual engagement of IgM and Toll-like receptors. Nature. 416:603-607.

30. Rui, L., Vinuesa, C.G., Blasioli, J., and Goodnow, C.C. 2003. Resistance to CPG DNA-induced autoimmunity through tolerogenic B cell antigen receptor ERK signaling. Nat. Immunol. 4:594-600.

31. Roosnek, E., and Lanzavecchia, A. 1991. Efficient and selective presentation of antigen-antibody complexes by rheumatoid factor B cells. J. Exp. Med. 173:487-489.

32. Kouskoff, V., et al. 1996. Organ-specific disease provoked by systemic autoimmunity. Cell. 87:811-822.

33. Reed, A.J., Riley, M.P., and Caton, A.J. 2000. Virusinduced maturation and activation of autoreactive memory B cells. J. Exp. Med. 192:1763-1774.

34. Djavad, N., et al. 1996. Comparison of rheumatoid factors of rheumatoid arthritis patients, of individuals with mycobacterial infections and of normal controls: evidence for maturation in the absence of an autoimmune response. J. Immunol. 26:2480-2486.

35. Borretzen, M., Chapman, C., Natvig, J.B., and Thompson, K.M. 1997. Differences in mutational patterns between rheumatoid factors in health and disease are related to variable heavy chain family and germ-line gene usage. Eur. J. Immunol. 27:735-741.

36. Viglianti, G.A., et al. 2003. Activation of autoreactive B cells by CpG dsDNA. Immunity. 19:837-847.

37. Stemmer, C., et al. 1996. Dual reactivity of several monoclonal anti-nucleosome autoantibodies for double-stranded DNA and a short segment of histone H3. J. Biol. Chem. 271:21257-21261.

38. Cobbold, S.P., Martin, G., and Waldmann, H. 1990. The induction of skin graft tolerance in major histocompatibility complex-mismatched or primed recipients: primed $\mathrm{T}$ cells can be tolerized in the periphery with anti-CD4 and anti-CD8 antibodies. Eur. J. Immunol. 20:2747-2755. 